\title{
ACERCAMIENTO A LA ESCRITURA ENSAYÍSTICA de Alfonsina Storni a la luz de la Performatividad DE GÉNERO DE JUDITH BUTLER
}

\author{
Angélica María Grajales Ramos ${ }^{1}$ \\ Universidad del Valle, Cali, Colombia
}

Resumen: Los ensayos Nosotras... y la piel (1919), Las dulces mujeres (1919) y El amor y la mujer (1920) de Alfonsina Storni, publicados en secciones femeninas de prensa, se configuran como textos con un estilo y discurso transgresor que ponen en cuestión los paradigmas androcentristas que definían la subjetividad femenina en la época. A partir de la noción de performatividad de género, propuesta por Judith Butler, se analizan estrategias enunciativas como la ironía y el uso de un seudónimo masculino por medio de las cuales Storni logra desarticular en estos ensayos el discurso prescriptivo que caracterizaba estas secciones y situarse en el terreno de los cuestionamientos sobre la identidad de género.

Palabras clave: Escritura heterodesignada; estrategias enunciativas; ideología de la domesticidad; Alfonsina Storni; ensayos.

Recibido: 18 de octubre de 2018

Aprobado: 22 de noviembre de 2018

ALFONSINA StORni's ESSAY Writing APPROACH IN LIGHT OF JUDITH BUTLER's gender performativity

Abstract: The essays Nosotras... y la piel (1919), Las dulces mujeres (1919) and El amor y la mujer (1920) of Alfonsina Storni, published in feminine sections of press, are configured as texts with a style and transgressive speech that They question the androcentric paradigms that defined feminine subjectivity at the time. From the notion of gender performativity, proposed by Judith Butler, we analyze enunciative strategies such as irony and the use of a masculine pseudonym by means of which Storni manages to disarticulate in these essays the prescriptive discourse that characterized these sections and situate oneself in the field of questioning about gender identity.

Keywords: Hetero-designation writing; enunciative strategies; ideology of domesticity; Alfonsina Storni; essays.

\footnotetext{
${ }^{1}$ Angélica María Grajales Ramos es Licenciada en Literatura y estudiante de segundo semestre de Maestría en Literaturas Colombiana y Latinoamericana de la Universidad del Valle. Correo electrónico: angelgra22@gmail.com
} 


\section{Acercamiento a la escritura ensayística de Alfonsina Storni a la luz de la performatividad de género de Judith Butler}

La escritura ha sido un terreno de lucha y legitimación para las mujeres. En la escritura las mujeres han encontrado posibilidades, entre otras, de construir identidades en la diversidad de lo que puede significar ser mujer, de pronunciarse y ganar un espacio en la discusión sobre temas que les competen como ciudadanas. Sin embargo, este proceso ha sido complejo y ha implicado para las escritoras el tener que amoldarse a ciertos condicionamientos de género, asentados en el imaginario y derivados de un discurso heteropatriarcal que termina por hacerse palpable en lo que puede o no decirse y en las formas de lo escrito. Con todo, y aunque podría darse por sentado que estos condicionamientos han limitado las posibilidades expresivas, escritoras como Alfonsina Storni - a quien abordaremos en esta reflexión-, han hallado en los textos de corte ensayístico maneras de instalar y modelar un discurso crítico que resiste a los intentos de estereotipar lo que se designa como femenino desde la postura oficial androcéntrica.

Si bien su prestigio literario deriva del inmenso reconocimiento que obtuvo su poesía por parte de la crítica, Alfonsina Storni incursionó también en géneros como la dramaturgia, el cuento, la crónica y el ensayo. Sus obras adscritas a estos dos últimos géneros han sido recopiladas y estudiadas en trabajos de doctorado como el de Claudia Méndez, titulado Alfonsina Storni: análisis y contextualización del estilo impresionista en sus crónicas publicado en 2004 y el de Alicia Salomone titulado Subjetividad femenina y experiencia moderna en la escritura de Alfonsina Storni publicado en 2005. Estudios que, entre otras cuestiones, han dejado ver que la obra ensayística de Alfonsina Storni tiende fuertes lazos con el periodismo, pues fue precisamente en medios escritos como periódicos y revistas literarias donde los editores le concedieron espacios de opinión para escribir sobre determinados temas de interés, particularmente femenino, de la época. Para ese momento, Storni ya venía mostrando una postura feminista, calificativo que incluso se dio a algunos de sus poemas, por lo que la posibilidad de escribir en medios de amplia circulación y en secciones destinadas a tratar temas relativos a la feminidad constituyó una oportunidad de llevar 
a cabo una crítica con un estilo literario muy particular a los estereotipos femeninos en boga. Estilo que, con el propósito aparente de modelar un tipo específico de mujer acorde con la moral y las buenas costumbres, se propuso en realidad subvertir los paradigmas sexogenéricos que se promovían en las secciones femeninas de la prensa.

De acuerdo con lo anterior, esta reflexión se ocupará del análisis de los ensayos Nosotras y la piel..., Las dulces mujeres y El amor y la mujer que Alfonsina Storni publicó en las secciones Feminidades y Bocetos femeninos de la revista literaria La Nota y el periódico La Nación respectivamente entre 1919 y 1920. En los cuales asume diversas posturas enunciativas que ponen en escena una actuación de género que le permite plantear un cuestionamiento respecto a la forma en que las mujeres se percibían a sí mismas a partir de determinados condicionamientos prescritos por la sociedad como parte de una concepción hegemónica de la diferencia sexual. Dicha actuación de género puede entenderse a la luz del carácter performativo del género que propone Judith Butler, que será la perspectiva teórica que orientará el análisis de los ensayos mencionados.

Con referencia al género ensayístico al que adscriben los textos de los que nos ocuparemos en esta reflexión, conviene recalcar que el discurso ensayístico "es literatura de ideas y, como tal, portador de dos categorías diferentes, la didáctica-lógica y la literaria, que en su entrecruzamiento hacen del género un objeto híbrido" (Urriago Benítez 65). En concordancia, la categoría didáctico-lógica refiere al uso pragmático de la lengua con una finalidad persuasiva, mientras la categoría literaria refiere a la voluntad de estilo o intención estética.

Concretamente, los tres ensayos de Alfonsina Storni que se han seleccionado para el análisis también han sido catalogados como columnas o artículos de opinión, lo cual pone de manifiesto el nexo del discurso ensayístico de Storni con el periodismo. Pero, por otra parte, nos remite a la clasificación que Antonio Casas, con base en los planteamientos de Gerard Genette, hace de este llamándolo archigénero ensayístico, en el que se agrupan "géneros como el comentario, la reseña, el artículo de opinión o la crítica literaria” (Urriago Benítez 37), en cuya acción discursiva prima la dimensión perlocucionaria vinculada 
a "la intencionalidad reflexivo-persuasiva connatural a los distintos géneros históricos susceptibles de ser agrupados bajo el marbete de ensayísticos" (Casas 315).

Este tipo de ensayos, además de ser escritos en prosa, con predominio de un discurso libre y reflexivo, tono personal y lenguaje no especializado, también se caracterizan por ser esencialmente polémicos. Aspecto en el que se cifra el lazo más fuerte que los ensayos de Storni tienden con el lenguaje periodístico, específicamente con el discurso de opinión, en tanto en ellos la autora logra unificar en su discurso crítico sus puntos de puntos de vista y su perspectiva artística sobre los temas que la ocupan.

Por otra parte, en el discurso ensayístico, como plantea Hernández González, la fábula de los textos ficcionales es "sustituida por una lógica original, una persuasión, construida con elementos estéticos tales como la ironía o la metáfora" (178). De modo tal que la proximidad del ensayo con la ficción tiene lugar en el terreno de la retórica literaria, donde la ironía juega un papel determinante y es uno de los instrumentos por excelencia de los que se sirve el ensayista, en este caso Alfonsina Storni. De hecho, la etimología de la palabra ironía revela que proviene del griego "eironéia" que significa ficción, o el que simula ignorancia, y de "éiron", el que pregunta y esconde la opinión propia. Por ende, dicha figura retórica está ligada al acto de fingir o simular, "ocultando una convicción y usando la interrogación en lugar de la forma aseverativa". (Id. 165). A este respecto y teniendo en cuenta el concepto de performatividad de género que los ensayos de Alfonsina Storni ponen en escena, en el análisis de los ensayos aquí abordados veremos que la ironía es uno de los recursos retóricos al servicio de dicha performatividad.

\section{Performatividad de género según Judith Butler}

En 1990, en su libro El género en disputa. El feminismo y la subversión de la identidad, la filósofa estadounidense Judith Butler planteó por primera vez el concepto de performatividad de género. En ese momento, Butler se propuso, por una parte, efectuar una crítica al heterosexismo que imperaba en la teoría feminista tradicional y, por 
otra, abogar por un reconocimiento y una existencia habitable para quienes viven a una cierta distancia de las normas de género y en una constante confusión o disputa con los paradigmas esencialistas desde los cuales se ha pretendido estabilizar la concepción y vivencia del género. La autora entonces empieza a considerar el género como un estilo corporal, un acto, que es al mismo tiempo intencional y performativo; donde lo performativo alude a una construcción contingente y dramática del significado (Butler 2007 271). Planteamiento que complementa señalando que:

El género es una construcción que reiteradamente disimula su génesis; el acuerdo colectivo tácito de actuar, crear y garantizar géneros diferenciados y polares como ficciones culturales queda disimulado por Ia credibilidad de esas producciones y por las sanciones que acompañan al hecho de no creer en ellas; Ia construcción nos «obliga» a creer en su necesidad y naturalidad. Las opciones históricas materializadas a través de distintos estilos corporales no son sino las ficciones culturales reguladas de forma punitiva, que alternadamente se personifican y se desvían bajo coacción. (Id. 272)

De ahí que los actos de género o la actuación de género siempre tienen lugar bajo una situación de coacción derivada de la matriz heterosexual y que, por consiguiente, tiene consecuencias punitivas para quienes se apartan de ella. Esto conduce a Butler a hablar de una sedimentación de normas de género a partir de las cuales surgen las concepciones de un «sexo natural» o de una «mujer real», que ella denomina como ficciones sociales constantes e impositivas, en el sentido que han creado "una serie de estilos corporales que, de forma reificada, se manifiestan como la configuración natural de los cuerpos en sexos que existen en una relación binaria uno con el otro" (Butler 2007 273).

Ahora bien, los presupuestos de Judith Butler sobre la performatividad de género son aplicables al análisis de los ensayos y columnas de prensa de Alfonsina Storni arriba mencionados, en primer lugar, porque permiten comprender las normativas sexogénericas que se han instituido y naturalizado como presuposiciones para entender lo femenino y para dictaminar el accionar de las mujeres, directriz a la que, por lo demás, adscriben las columnas femeninas en los medios 
escritos de la época. En segundo lugar, porque permite dilucidar en el espacio de lo escrito, concretamente en las estrategias enunciativas de Storni, los momentos en los que se disputa y se reta el sistema binario del género cuestionando la coherencia de las categorías sexogenéricas; cuyas ideologías se filtran en las formas de la escritura y en lo que la escritura debe decir para llenar las expectativas de un destinatario al que simultáneamente se está modelando, es decir, a un tipo particular de mujer doméstica.

Lo anterior nos lleva a la noción de parodia de género que plantea Butler, según la cual, el género en tanto acto: "Está abierto a la parodia y crítica de uno mismo o una misma y a las exhibiciones hiperbólicas de «lo natural» que, en su misma exageración, muestran su situación fundamentalmente fantasmática" (Butler 2007 285). Al presentarse como una imitación de los modelos normativos imperantes, la parodia abre el espacio a una fluidez de identidades mediante la cual opera una resignificación y recontextualización paródica que impide a la cultura hegemónica y a su crítica confirmar la existencia de identidades de género esencialistas o naturalizadas (Id. 269). Una vez establecido este marco, más adelante nos será posible examinar cómo en las secciones Feminidades y Bocetos femeninos Alfonsina Storni, en el rol de columnista de opinión —usando términos contemporáneos - despliega una serie de ejercicios de escritura en los que lo crítico y lo creativo se entretejen y donde puede rastrearse una recontextualización paródica con la que subrepticia o abiertamente plantea un cuestionamiento en torno a la percepción de lo femenino.

\section{Escritura de mujeres para mujeres}

Antes de adentrarnos en el análisis de los ensayos de Alfonsina Storni, conviene caracterizar las secciones femeninas de los periódicos y revistas, muy comunes en los medios escritos de la época y donde hubo una configuración enunciativa clara a la que las escritoras tuvieron que adaptar su intención comunicativa. Tania Diz denomina artículos femeninos "a las notas periodísticas, generalmente columnas, firmadas con seudónimos femeninos que tenían por referente y lectora a la mujer" (Diz 2006 31) Estos artículos orientaban la constitución de 
la mujer o de lo femenino a partir de dos ejes fundamentales: el primero atiende al cuerpo desde parámetros de la salud, de la moda o de la vida social; y el segundo a las tipologías a partir de las cuales se describía y evaluaba la subjetividad femenina. A este segundo eje suscriben los artículos de Storni.

Según Diz, los escritos de este segundo eje se caracterizaban por hacer uso de un lenguaje coloquial que daba lugar a una proximidad identitaria entre enunciadora y enunciataria o, en otros términos, a un efecto de identificación. Se encuentran así artículos donde se diluyen las fronteras entre la realidad y la ficción, en los que pueden leerse fragmentos de diarios íntimos, cartas entre amigas o descripciones de tipos femeninos como la joven casadera, la novia, la esposa y la madre, entre otras (Diz 2006 32).

En un estudio posterior que antecede a una compilación de ensayos y textos periodísticos de Storni en 2014, Tania Diz introduce el asunto de la ideología de la domesticidad que es reforzada y promovida a través de las columnas o artículos femeninos de la época. A partir de esta ideología, la identidad es pensada en función de dos sexos únicos, distintos y excluyentes entre sí, al tiempo que se promueve un modelo de familia nuclear, todo esto vinculado con la necesidad de organizar y controlar la sociedad. En ese imperativo de ordenar, la mujer deviene en un sujeto clave, pero por lo general restringido a espacios domésticos o de sociabilidad, y con una actitud y posición de necesaria subordinación respecto al hombre. Todo este panorama coincide con la expansión de la industria editorial y con la emergencia de la mujer como lectora, producto de las políticas alfabetizadoras del estado en la Argentina de principios del siglo XX, en pleno proceso de modernización.

Al examinar esta dinámica enunciativa de las columnas o artículos femeninos es posible entrever una heterodesignación de la escritura, en la que la mujer que escribe a su vez prescribe formas adecuadas de feminidad a una mujer que lee y recurre a estas columnas en espera de hallar instrucciones para orientar su hacer en el mundo. La lectora de este tipo de artículos es descrita por Diz como:

Una mujer joven que se desplaza del barrio al trabajo, al cine (...), cuya vida está marcada por la tensión entre el sentimentalismo román- 
tico y la monotonía de la vida de soltera en la casa paterna (...), lectora por excelencia de las novelas por entregas o folletines. (Diz 2014 8)

Entretanto, la autora o escritora de estas columnas: "adopta un tono estereotipadamente maternal, de cierta superioridad amorosa con la que se dirige a la lectora que ocupa un lugar de subordinación cómplice" (Id. 9).

Storni desde la década de 1910 se vincula a los medios periodísticos como una forma de subsistencia económica que su carrera literaria no le ofrecía por completo. Sin embargo, no ingresa en ellos comulgando del todo con el discurso que se impulsaba a través de estas tribunas de opinión femenina, por lo que perspicazmente fue instalando su estilo y preocupaciones particulares como mujer. En forma gradual, Alfonsina Storni se propondría "desbaratar los preceptos que subyacen a este espacio y, por este medio, interrogar el ideal de femineidad sobre el que construye su autoridad la columna/página femenina" (Méndez 179).

\section{Subversiones de la feminidad}

El análisis de la puesta en escena en el espacio textual y enunciativo de la noción de performatividad de género de Butler implica examinar la forma cómo Alfonsina Storni, en su rol de ensayista, se posiciona frente a los temas y situaciones que discute en cada uno de los ensayos que abordaremos. Si recurrimos a una paráfrasis del título del primer libro que Butler publicó sobre la cuestión de género, podemos afirmar que los ensayos de Storni dan lugar a una disputa con los condicionamientos de género que tradicionalmente se asignaban a la mujer en su hacer en sociedad, pero al mismo tiempo establecen una disputa con los parámetros a los que debían regirse las escritoras que se hacían cargo de las secciones femeninas de prensa. Es en ese sentido que la escritora en cuanto ensayista toma una posición crítica que se expresa en el modo de discutir abierta o veladamente los temas que la inquietan, en el modo de interpelar tanto a mujeres como a hombres, en las formas textuales y voces enunciativas que elige para su escritura.

En el ensayo Nosotras... y la piel, publicado el 25 de abril de 1919 en la sección Feminidades de la revista La Nota, Alfonsina Storni discute en torno a la correlación que la sociedad de la época establecía entre 
moralidad femenina y moda a partir de la cual quiso instituir preceptos para una vestimenta femenina recatada. La crítica de la ensayista se origina y apunta a controvertir "Una disposición municipal prohibiendo a los bailarines que aparezcan en el tablado con las piernas sin mallas y a una liga de señoras contra la moda, para evitar los excesos del descubierto" (Storni, Escritos 75). En los comentarios iniciales del texto leemos:

Se ha descubierto no sé qué íntima relación entre la moralidad femenina y la piel; se lo ha descubierto ahora, en pleno siglo veinte, cuando ya nos permitíamos, las osadillas, decir en voz alta que conocemos a un escritor que se llama Maupassant. ¡Oh desgracia!

Correremos desde hoy mismo hacia las tiendas, pediremos muchos metros de tela para hacernos vestidos especiales, usaremos pesado velo en la cara, nos pondremos guantes de dos centímetros de espesor en las manos... ¡Oh desgracia mayor! (75).

En este ensayo veremos entonces que la autora desde un principio se vale de la ironía para deconstruir ese discurso moralizante que se impone desde las esferas de poder instruyendo sobre lo adecuado en el vestir, pero, al mismo tiempo, imponiendo restricciones que terminan por permear las manifestaciones culturales y limitar el acceso y la libre expresión de las mujeres. Además, con la mención a Maupassant, Storni plantea una paradoja para enfatizar lo contradictorio de que en pleno siglo XX, cuando las mujeres leen a hurtadillas literatura erótica e, incluso, lo reconocen públicamente, se quisiera instaurar un discurso moralizante de la moda. De manera implícita la crítica de la autora va poniendo de manifiesto una vivencia del género bajo una situación de coacción, aspecto que remarcaba Butler en relación con la performatividad.

A medida que avanza en su reflexión Storni interpela a sus lectoras, a quienes está informando de una circunstancia poco conveniente para ellas: "Resulta, pobres de nosotras, que mucha parte de la dignidad y el pudor femeninos lo tenemos en la piel, a la que no podemos ni lucir ni mirar sin que nuestra moral sufra descalabro" (76). La expresión "pobres de nosotras" acentúa el tono irónico del discurso y subraya las prohibiciones a las que se ven expuestas en la escena social: 
Hasta hoy yo había pensado que la moral femenina era mucho más profunda, más valiosa, más completa.

Me había permitido soñar que podíamos ir a una sala de espectáculos y resucitar a la Grecia maravillosa en un púdico desnudo... había creído que teníamos el derecho de ir a los museos y olvidarnos de todo ante la presencia de un mármol perfecto, había soñado con que eso era tan nuestro como el agua que bebemos... Había creído que de esa sensación de arte resurgiríamos elevadas y dignas, capaces de entender, la divinidad, capaces del perdón, del sacrificio, de todos los más grandes sentimientos humanos, y he aquí que los hombres descubren en la piel y en el desnudo las propiedades de Satán y quieren salvarnos, oh protegidas mujeres, de sus maléficos peligros, poniendo entre Satán y los ojos una malla de seda muy transparente, muy fina, muy sugestiva... (76)

De esta manera, Storni objeta la concepción de moralidad femenina que proviene del discurso religioso y estatal cuya influencia busca materializarse tanto en las manifestaciones artísticas como en los atuendos femeninos con la excusa aparente de proteger a la mujer. Ella vista en el trasfondo de este discurso como un ser indefenso que debe estar al resguardo de todo aquello que pueda llevarla a apartarse del estereotipo de mujer doméstica imperante, o dicho de otro modo, a pensar y expresarse libremente.

Hacia el cierre de este ensayo Storni retoma el asunto de la "liga de señoras contra la moda" (76) para recalcar la inutilidad de su existencia en comparación con temas más prioritarios y de conveniente discusión: "Emprenderla en cátedra severa contra la moda, por ejemplo, mientras se descuidan problemas fundamentales de la vida, en el sentido económico y educacional, me parece lo mismo que ponerse a vaciar el mar con un mal jarrito de niño" (76). Por ello concluye interpelando a dichas señoras: "La moda, señoras, es un simple y liviano sarpullido inofensivo las más de las veces" (Ibid.).

En este ensayo, como en el que examinaremos a continuación, Alfonsina Storni lleva a cabo un ejercicio reflexivo y crítico en el que puede percibirse la intención de alterar y desplazar aquellas nociones de género naturalizadas que sustentan la hegemonía masculina y el poder heterosexista a las que se refería Butler y que, como podemos inferir de este texto en particular, son legitimadas por las mismas mujeres: 
el caso de las señoras de la liga contra la moda y los trajes que dejan piel al descubierto. Así, la ensayista apela a un tema de actualidad para polemizarlo valiéndose de la ironía y de la exageración: "Iremos... sin alzar los ojos, no miraremos a ningún lado cuando vayamos por las aceras e inmoladas en ese púdico sacrificio caeremos víctimas de un auto veloz. ¡Oh romántica y pura muerte de una niña del siglo veinte!” (75).

Las dulces mujeres es el título del ensayo publicado el 12 de septiembre de 1919 en la revista La Nota. En él, Alfonsina Storni establece una tensión alrededor del calificativo "dulces mujeres" popularizado por los poetas, y quiere poner en evidencia la heterodesignación que hay detrás de este aparente elogio que, por el contrario, ha sido usado para reforzar en el imaginario la concepción de la mujer como el sexo débil. La autora da inicio a la discusión con las siguientes reflexiones:

Las dulces mujeres tenemos sobre la tierra donde nos movemos, una historia poco edificante. Debe ser por eso, justamente, que los poetas son nuestros amigos. Adorados sean ellos. Pero no confiemos demasiado en lo que los poetas digan; ya sabemos cómo estos extraños y lunáticos seres viven en los planos astrales (Storni, Escritos 123).

Con la frase "una historia poco edificante" Storni deja claro desde un primer momento el rumbo hacia el que dirigirá su argumentación, en la que enseguida se posiciona, junto a sus lectoras, bajo la denominación de mujeres modernas:

A las mujeres modernas - un poco desorbitadas; oh, no lo dudamos, ni nos ofende el concepto- nos causa, así como piedad toda esta nube de alabanzas que la mujer ha levantado alrededor de su belleza, del placer que proporciona, de la resignación y sacrificio de que se anima en la vida (123).

Mujeres modernas que, en otros términos, Storni presupone como capaces de trascender críticamente los condicionamientos que se les asignan como producto de la concepción binaria del género. Por ello, en el inciso trae a colación otro calificativo que se les atribuye: "un poco 
desorbitadas", con el que sin embargo no riñe, para en cambio subrayar la "piedad", o displicencia, que genera en ellas los pretendidos halagos.

Con el propósito de ahondar e ilustrar ese "lugar poco edificante" al que la historia y el discurso androcentrista han relegado a la mujer, Storni introduce el tema del matrimonio, el cual desde su perspectiva: "Nos daría, sin ir más lejos, muchas pruebas concluyentes de la pobre condición femenina, frente a la vida del espíritu. Desde siglos atrás, tomando al caso cualquier nación, resalta la inferioridad del sexo débil" (123).

De este modo, Alfonsina acude a una serie de ejemplos relativos a la forma como los asirios, los semitas, los hindúes, el pueblo circasiano, los serbios y los búlgaros casaban a sus mujeres. Y hace hincapié en la cosificación de la mujer al ser tratada como un objeto expuesto al mejor postor en remates, reparticiones o como premios otorgados a los varones por sus méritos, sin considerar en absoluto su opinión. Entre estos ejemplos, para recalcar el uso de la ironía, destaca la referencia al matrimonio en la cultura hindú:

En los "mantras", especie de código religioso que el brama lee a la pareja a quien casa, se expresa: "El esposo es el Dios de su mujer; por viejo, feo o malo que sea, o que se vuelva, debe ser el ídolo del corazón de su mujer; todos los deseos de ésta han de ser conformes a los del marido; esto es, reír si el marido ríe, llorar si llora, guardar silencio si calla" (124).

Luego de citar este ejemplo, complementa con un comentario dirigido esta vez al público masculino: "Quedan pues prevenidos los gruñones que deseen contraer matrimonio y obtener sumisión completa: lo único que deben hacerse es... un viaje a Calcuta" (124). El ensayo finaliza señalando que dada la vastedad del tema lo retomará en un próximo artículo: "No sin antes anticipar que las civilizaciones europeas y americanas han dignificado grandemente a la mujer. Pero, claro está, que aún nos queda mucho que andar antes de creernos con el generoso poeta 'las dulces mujeres"' (124).

Además de la ironía, otra de las estrategias enunciativas a las que acude Alfonsina Storni en sus ensayos publicados en la sección Bocetos 
femeninos del diario La Nación es el enmascaramiento de la autoría o la asunción de una identidad masculina bajo el seudónimo Tao Lao. El uso de este seudónimo constituye una ficcionalización del enunciador (Diz 2006 104), de la que la ensayista se servirá para manejar su posicionamiento frente a determinados temas y hablar de ellos con mayor autoridad o conocimiento de causa. Esto, considerando que Tao Lao es caracterizado por Storni en otro ensayo como como un viejo chino que conoce muy bien a las mujeres debido a que se casó en tres oportunidades.

Uno de los ensayos en los que Tao Lao asume la voz enunciativa se titula El amor y la mujer, publicado el 22 de agosto de 1920, en donde el uso de la ironía y el humor se manifiestan de manera más explícita en la argumentación, dando cuenta de la construcción de un sujeto de la enunciación cuya identidad sexual está exacerbada (Diz 2014 18). En consecuencia, este sujeto enfoca sus reflexiones a poner en tela de juicio los discursos que la posición hegemónica androcentrista ha instituido como verdades y que las secciones femeninas de la prensa ayudaban a cristalizar en el imaginario colectivo. En El amor y la mujer Tao Lao aborda la experiencia del amor desde la perspectiva femenina, partiendo del supuesto que sus lectoras podrían irritarse con lo que ha de decir:

Empiezo este artículo con el paraguas abierto... Pero os ruego, oh divinas, que no hagáis llover sobre mí, otra cosa que flores... Ya estoy con vuestras flores sobre las manos, y gratamente embriagado por su perfume puedo hablar del amor, y de vosotras, y de cómo lo concebís.

Regocijaos por lo pronto, de ser todavía las celosas vestales del romanticismo. (Es muy lindo ser vestal, el tul blanco cae divinamente y lame el rosado pie, con delicada gracia) (Storni, Escritos 146).

Más adelante en su reflexión, luego de hacer una digresión en torno a lo que un romántico, un cínico, un escéptico, un espiritualista y un lírico concebirían particularmente como el amor: Tao Lao vuelve a las mujeres para decir: "Ellas han dicho desde antiguo la última palabra en amor: es decir, que el amor debe vivirse y no comentarse; con la ventaja de que, para dar a entender esto, ni siquiera emplearon palabras, se valieron de 
los hechos" (Storni, Escritos 147). Con expresiones como las siguientes que hemos subrayado: "Se dice contra vosotras, que quedáis aferradas a la vida... defendiendo el amor con ferocidad instintiva, adorándolo como razón principal de la existencia, embelleciéndolo, adornándolo..., deseándolo ardiente y enorme, avasallante y ciego, por incapacidad intelectual para la vida desde afuera..." (Ibid.) o "Comparan la condición voluptuosa de la mujer a la de ciertas razas inferiores que viven solamente para amar y satisfacer sus pasiones, y hasta pretenden que el alto sentimiento de la maternidad es instinto puro" (Ibid.), Tao Lao empieza a tomar distancia crítica de los imaginarios generalizados que supeditan a la mujer a un lugar de inferioridad y que le asignan un rol instintivo en contraposición a la racionalidad masculina. Lo anterior se confirma con el siguiente enunciado:

Con lo que resultáis, nada menos, que el lastre de la humanidad, la fuente, el pozo sentimental y básico, en que el hombre cae, y se renueva después de haberse apartado de la vida, volando por las altas regiones del pensamiento (147).

Tao Lao finaliza su reflexión retomando la ironía del inicio y aludiendo de nuevo a sus lectoras: "Y no digáis ahora que no os he vengado del razonamiento masculino... Cierro el paraguas, pues, por si aún permanecierais en enojo conmigo, os declaro ahora que no os temo enojadas, sino mansas y suaves" (148). Lo cual deja ver que la intención de Tao Lao, si bien encubierta en el inicio del ensayo, era la de tomar posición a favor de las mujeres.

\section{Conclusiones}

En este recorrido por los ensayos Nosotras... y la piel, Las dulces mujeres y El amor y la mujer hemos podido apreciar la disputa que Alfonsina Storni establece con los condicionamientos de género a partir de los cuales se concibe y se juzga el accionar femenino en la época que la poeta y ensayista escribe para medios periodísticos. Una disputa que se instala en el terreno de las estrategias enunciativas y que subvierte el estilo y el discurso que caracterizaba las columnas de opinión 
femeninas, por medio de las cuales se promovía entre las lectoras el ideal o estereotipo de mujer doméstica.

En este sentido y particularmente en ensayos como los que se abordaron, Storni apunta a revertir las expectativas de las lectoras, por lo general acostumbradas a encontrar en estas secciones recetas de cocina, consejos de belleza o prosa didáctico-moralizante que orientara a las madres en la crianza de sus hijos, el cuidado de sus esposos, o en el caso de las jovencitas en la búsqueda de pretendientes. Lo que se encuentran, en cambio, es a una mujer y a un hombre (Tao Lao) que, en un tono irónico, satírico y en algunas ocasiones cómico habla de asuntos como la moda y la moralidad femenina, el lenguaje y los discursos aparentemente apologéticos que han reforzado el imaginario de la mujer como el sexo débil y que la han juzgado como ser instintivo y pasional. Alfonsina deviene así en una figura transgresora para su época por cuanto sus ensayos esbozaron asuntos que han sido y continúan siendo objeto de discusión en el feminismo contemporáneo.

Asimismo, estos ensayos escenifican lo que Judith Butler denomina la performatividad de género en tanto resignifican y recontextualizan las secciones femeninas de la prensa logrando poner en evidencia los términos que se naturalizan y esencializan como presuposiciones para entender lo femenino. De hecho, si examinamos las expresiones que nominaban las secciones en las que se publicaban los ensayos y crónicas de Storni, Feminidades en la revista La Nota y Bocetos femeninos en diario La Nación, podríamos inferir un imperativo que restringe y encamina la enunciación hacia la definición de lo femenino, imperativo que la ensayista emplea creativamente para despertar otras inquietudes en sus lectoras al trascender el discurso prescriptivo y situarse en el terreno de los cuestionamientos sobre la construcción de la identidad de género. Esto nos remite a lo que Judith Butler señala respecto a la práctica de la performatividad de género: "En la que no sólo podemos observar cómo se citan las normas que rigen la realidad, sino que también podemos comprender uno de los mecanismos mediante los cuales la realidad se reproduce y se altera en el decurso de dicha reproducción" (Butler 2006 308). 


\section{Referencias}

Butler, Judith. Deshacer el género. Barcelona: Paidós, 2006. Impreso.

Butler, Judith. El género en disputa: el feminismo y la subversión de la identidad. Barcelona: Paidós, 2007. Impreso.

Casas, Arturo. «Breve propedéutica para el análisis del ensayo.» 1999. Ensayistas.org. Digital. <https://www.ensayistas.org/critica/ensayo/casas.htm>.

Diz, Tania. Alfonsina periodista: Ironía y sexualidad en la prensa argentina (1915-1925). Buenos Aires: Libros del Rojas, Universidad de Buenos Aires, 2006. Impreso.

Diz, Tania. «Feminidades insurgentes.» Storni, Alfonsina. Escritos. Imágenes de género. Buenos Aires: Editorial Universitaria Villa María, 2014. Impreso.

Hernández González, Belén. «El ensayo como ficción y pensamiento.» Adsuar Fernández, María Dolores, Belén Hernández González y Vicente Cervera Salinas. El ensayo como género literario. Murcia: Universidad de Murcia, Servicio de publicaciones, 2005. 143-178. Impreso.

Méndez, Mariela. «Aliadas e insurrectas: Las Columnas Femeninas de Alfonsina Storni y Clarice Lispector.» Alzate, Carolina y Darcie Doll. Redes, Alianzas y Afinidades. Mujeres y Escritura en América Latina. Santiago de Chile: Universidad de los Andes, Universidad de Chile, 2014. 177—193. Impreso.

Storni, Alfonsina. Escritos: imágenes de género. Estudio preliminar de Tania Diz. Villa María: Eduvim, 2014. Impreso.

Urriago Benítez, Hernando. El signo del centauro: variaciones sobre el discurso ensayístico de Baldomero Sanín Cano. Cali: Programa Editorial Universidad del Valle, 2007. Impreso. 